\title{
Acute blood glucose fluctuation enhances rat aorta endothelial cell apoptosis, oxidative stress and pro-inflammatory cytokine expression in vivo
}

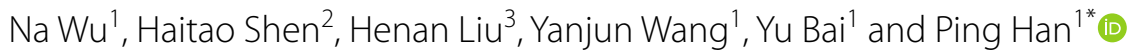

\begin{abstract}
Background: Complications of diabetes mellitus (DM) are related not only to elevated plasma glucose, but also plasma glucose fluctuations. However, the specific mechanism underlying the role of plasma glucose fluctuation in the pathogenesis of DM complications remains poorly understood. In the present study, the influence of acute fluctuant hyperglycemia and persistent hyperglycemia on vascular endothelial cell apoptosis, function, oxidative stress and inflammation was examined in vivo.
\end{abstract}

Methods: Rats were assigned to three different groups ( $n=10 /$ group) that received 48 - $h$ infusions of saline (SAL group), continuous $50 \%$ glucose (constant high glucose group [CHG]), or intermittent $50 \%$ glucose (acute blood glucose fluctuation group [AFG]). Plasma 8-isoprostaglandin, interleukin-6 (IL-6), tumor necrosis factor-a (TNF-a) and intercellular adhesion molecule-1 (ICAM-1) levels were quantified by using enzyme-linked immunosorbent assay (ELISA) commercial kits. Plasma insulin levels were measured by radioimmunoassays (RIAs) using kits. The aortic segment was collected. The levels of malondialdehyde (MDA) and activity of glutathione peroxidase (GSH-PX) were measured in endothelial homogenates prepared from endothelial cells harvested from the aorta using colorimetric kits. Apoptosis of vascular endothelial cells was determined with terminal deoxynucleotidyl transferase dUTP nick end labeling (TUNEL). Endothelial dysfunction was assessed by isometric tension recording to evaluate the endothelial function. The expression of B cell lymphoma-2 (BCl-2), BCl-2 Associated X protein (Bax), pro caspase-3, caspase-3 p17, 3-nitrotyrosine (3-NT) and p47phox protein in rat aortic endothelial cells were tested with Western blot analysis. Endothelial cells reactive oxygen species (ROS) formation was determined using dihydroethidium-dependent fluorescence microtopography in aortic cryo-sections. Expression of IL-6, TNF- $a$ and ICAM-1 mRNAs in vascular endothelial cells were determined by real-time quantitative PCR.

Results: Endothelial cells apoptosis and dysfunction were observed significantly in the aortas of the AFG group $(\mathrm{P}<0.05)$. The AFG had reduced $\mathrm{BCl}-2$ and pro caspase-3 levels and enhanced Bax mitochondrial translocation and caspase-3 p17 protein levels in comparison with the CHG group $(P<0.05)$. Both AFG and CHG induced $\beta$-cell dysfunction and insulin resistance $(P<0.05)$. AFG increased MDA and 8-isoprostaglandin levels in plasma, oxidative stress in vascular endothelial cells, and inflammatory cytokines in plasma and vascular endothelial cells $(P<0.05)$.

Conclusion: Acute glucose fluctuation may cause significant oxidative stress and inflammation in endothelial cells, increase the adhesion of monocytes to endothelial cells, and elevate endothelial cell apoptosis, resulting in severe cardiovascular injury.

\footnotetext{
*Correspondence: wun@sj-hospital.org

1 Department of Endocrinology, Shengjing Hospital of China Medical

University, Shenyang 110004 , China

Full list of author information is available at the end of the article
} 
Keywords: Acute blood glucose fluctuation, Endothelial cells, Apoptosis, Oxidative stress, Inflammation

\section{Background}

In recent years, studies have indicated that the occurrence and development of diabetes mellitus (DM) complications are closely related to not only elevated plasma glucose (PG), but also fluctuations in PG [1]. Compared to persistent hyperglycemia, fluctuant hyperglycemia has more potential to increase microvascular lesions and the risk of cardiovascular death [2-4], but the specific mechanism is still unclear. Blood glucose fluctuation exists not only in diabetes, but also in individuals with normal metabolic function. In the condition of stress, the glucose levels of those with normal metabolic function may be very high. In this case given hypoglycemic therapy, there may be glucose decreases sharply in the hypoglycemic process, leading to acute glucose fluctuations. We had successfully established acute blood glucose fluctuation model before $[5,6]$. Evidence indicates that oxidative stress and inflammation are the major mechanisms underlying the pathogenesis of DM complications. The vicious cycle of oxidative stress and inflammation may damage cells, and increasing evidence suggests that acute PG fluctuation may induce oxidative stress in vivo [5].

Endothelial dysfunction is a key pathophysiological step in the early stage of vascular DM complications [7-9]. Previous studies have demonstrated that vascular dysfunction in the setting of diabetes is associated with increased vascular oxidative stress and low-grade inflammation [10-12]. Early in vitro studies showed that fluctuant hyperglycemia could increase the apoptosis of human umbilical vein endothelial cells $[13,14]$ and induce inflammation [15]. In recent years, in vitro studies have also indicated that fluctuant hyperglycemia may increase apoptosis, oxidative stress [16] and inflammation $[17,18]$ of human coronary artery endothelial cells (HCAECs). Mita et al. [19] demonstrated that swings in blood glucose levels accelerated atherogenesis in apolipoprotein E-deficient mice. In Mita T's study, apolipoproteine-deficient mice fed maltose twice daily were used as a model of repetitive postprandial glucose spikes, which simulated chronic hyperglycemia in vivo. Blood glucose fluctuation exists not only in diabetes, but also in individuals with normal metabolic function. In the condition of stress,the glucose levels of those with normal metabolic function may be very high. In this case given hypoglycemic therapy, there may be glucose decreases sharply in the hypoglycemic process, leading to acute glucose fluctuations. To date, few studies have been conducted to investigate the influence of acute fluctuant hyperglycemia on endothelial cells in vivo. Our group had successfully established the acute fluctuant hyperglycemia animal model $[5,6]$, which was employed to investigate the effects of fluctuant hyperglycemia on endothelial cells.

In this study, glucose was intravenously injected into rats to establish animal models of acute fluctuant hyperglycemia and persistent hyperglycemia with the objective of exploring their influence on apoptosis, oxidative stress and inflammation of endothelial cells in vivo.

\section{Methods \\ Animals}

Normal male Wistar rats weighing 250-350 g (8-10 weeks old) were provided by the Medical Animal Center, Shengjing Hospital of the China Medical University (Shenyang, China). The rats were subjected to a standard 12:12-h light-dark cycle and were given free access to regular chow and water. All animal experiments were performed with approval from the animal ethics committee of Shengjing Hospital of China Medical University (2016PS026 K). All experiments conformed to guidelines for ethical conduct in the care and use of animals. Every effort was made to minimize stress to the animals.

\section{Animal surgeries}

Indwelling catheters (PE-50; Cay Adams, Boston, MA, USA), each extended with a 3-cm segment of silastic tubing with an internal diameter 0.02 in (Care Express Products, Inc., Cary, IL, USA), were inserted into the internal jugular vein of the rats for infusion and the carotid artery for blood sampling as described previously [20]. After surgery, the rats had 3-4 days of recovery before intravenous infusion.

\section{Intravenous infusions}

Food was withdrawn $12-14 \mathrm{~h}$ before each infusion. The rats were assigned to three different groups $(n=10 /$ group), each of which underwent 48-h infusions with (1) saline (5.5 mL/min; SAL group); (2) continual $50 \%$ glucose (blood glucose was monitored regularly to keep the glucose concentration at $20 \pm 0.5 \mathrm{mmol} / \mathrm{l}$, constant high glucose [CHG] group); or (3) intermittent $50 \%$ glucose (Every $15 \mathrm{~min}$, we measured the blood glucose level, and adjusted the glucose infusion rate according to the blood glucose monitoring. The blood glucose level alternated between $5.5 \pm 0.5$ and $20 \pm 0.5 \mathrm{mmol} / \mathrm{L}$. That is to say, control the glucose level at about $5.5 \mathrm{mmol} / \mathrm{l}$ for $1 \mathrm{~h}$, and then at $20 \mathrm{mmol} / \mathrm{l}$ for $1 \mathrm{~h}$, so the cycle. Acute blood glucose fluctuation [AFG] group) (Fig. 1). The procedures for infusion were followed as previously described [5]. 


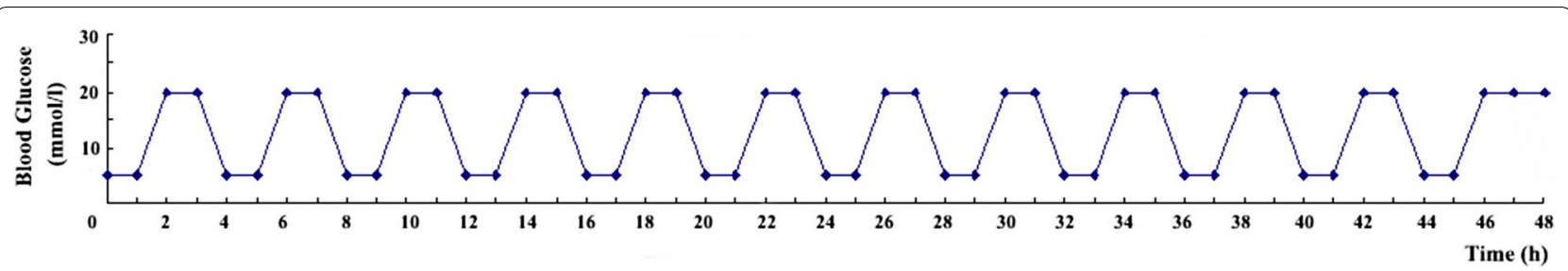

Fig. 1 Acute blood glucose fluctuation model. Blood glucose alternated between $5.5 \pm 0.5$ and $20 \pm 0.5 \mathrm{mmol} / \mathrm{l}$

\section{Plasma assays}

Glucose concentrations in plasma were measured with a Beckman Glucose Analyzer II (Beckman, Fullerton, Calif., USA). At the beginning and the end of the $48 \mathrm{~h}$ infusion, plasma insulin levels were measured by radioimmunoassays (RIAs) using kits specific for rat (Beijing Furui Biological Engineering Co, China). With plasma insulin and glucose levels, insulin resistance was estimated as homeostasis model of assessment for insulin resistence index (HOMA-IR) using HOMA Calculator v2.2.3 offered by University of Oxford. Insulin secretion ( $\beta$ cell function) was obtained as HOMA- $\beta \%$ using HOMA Calculator. Circulating oxidative stress, measured as the plasma concentration of 8-isoprostaglandin, was analyzed using an enzyme-linked immunosorbent assay (ELISA) commercial kits (Uscnlife, Missouri, TX, USA). The plasma levels of malondialdehyde (MDA) were measured using colorimetric kits (Nanjing Jiancheng Institute of Bio-engineering, China). Plasma interleukin-6 (IL-6), tumor necrosis factor- $\alpha$ (TNF- $\alpha$ ) and intercellular adhesion molecule-1 (ICAM-1) levels were quantified by using commercially available ELISA kits (Uscnlife, Missouri, TX, USA), according to the manufacturer's instructions.

\section{Tissue collection and preparation of endothelial cell homogenates}

After $48 \mathrm{~h}$ of infusion, rats were anesthetized with an intraperitoneal injection of chloral hydrate $(400 \mathrm{mg}$ / $\mathrm{kg}$ ). After blood collection, the animals were perfused with $100 \mathrm{~mL}$ of normal saline. Then, an aortic segment was collected to detect apoptosis, reactive oxygen species (ROS) formation and vascular function. Another aortic segment was collected, and vascular endothelial cells were harvested followed by extraction of protein for western blotting assay. The procedures for endothelial cell homogenate sample preparation were followed as previously described [21]. Briefly, after opening the aorta longitudinally and rinsing it with PBS, the inner surface was gently scraped with the tip of a scalpel to selectively isolate endothelial cells. The endothelial scrapings from each rat aorta were sonicated in $200 \mu$ l of ice-cold homogenizing buffer. The aortic endothelial homogenate was clarified by centrifugation $(13,800 \times g$ for $10 \mathrm{~min}$ at $4{ }^{\circ} \mathrm{C}$ ), snap-frozen and stored at $-80{ }^{\circ} \mathrm{C}$ for Western blot analysis. Protein concentrations were determined by the Coomassie brilliant blue G-250 dye-binding method.

\section{Terminal deoxynucleotidyl transferase dUTP nick end labeling (TUNEL) assay}

Paraffin-embedded aorta sections were processed for a terminal deoxynucleotidyl transferase dUTP nick end labeling assay with kits from Roche Company (Mannheim, Germany) according to the manufacturer's instructions. Sections were deparaffinized and rehydrated. After washing with PBS three times, all sections were incubated for $8 \mathrm{~min}$ in freshly prepared $0.1 \%$ Triton X-100 permeabilization solution with $0.1 \%$ citrate buffer and then washed with PBS. A TUNEL TdT enzyme reaction mixture $(50 \mu \mathrm{L})$ was added to each sample and incubated for $1 \mathrm{~h}$ in a humidifying chamber at $37{ }^{\circ} \mathrm{C}$. Slides were then washed and observed under a fluorescence microscope.

\section{Endothelial function studies}

We detected acetylcholine (Ach)-dependent vasodilatation by isometric tension recording to evaluate the endothelial function. Vasodilator responses to the endothelium-dependent vasodilator Ach were assessed in organ chambers by isometric tension studies, preconstricted with phenylephrine (PheE), as described previously, as previously described [22].

Western blot analysis of B-cell lymphoma-2 (Bcl-2), Bcl-2 associated $X$ protein (Bax), pro caspase-3, caspase-3 p17, 3-nitrotyrosine (3-NT) and p47phox protein expression

Endothelial cell homogenates containing equal amounts of protein were separated using SDS polyacrylamide gel electrophoresis (SDS-PAGE) and were transferred onto polyvinylidene fluoride (PVDF) membranes. To investigate the membrane association of soluble NADPHoxidase subunits $\mathrm{p} 47 \mathrm{phox}$, the lysates were separated into cytosolic and membrane fractions by ultracentrifugation $\left(100,000 \times g\right.$ for $1 \mathrm{~h}$ at $\left.4{ }^{\circ} \mathrm{C}\right)$. The membranes were 
blocked in Tris-buffered saline-Tween (TBST) containing $5 \%$ non-fat dried milk ( $\mathrm{pH}$ 7.4) for $2 \mathrm{~h}$ at room temperature and then incubated with one of the following primary antibodies: monoclonal mouse Bax (1:200, Santa Cruz Biotechnology, Santa Cruz, CA, USA), monoclonal mouse Bcl-2 (1:1000, Santa Cruz Biotechnology), monoclonal mouse caspase-3 (1:200, Santa Cruz Biotechnology), polyclonal goat caspase-3 p17, 1:1000, Santa Cruz Biotechnology), 3-NT (1:1400, Abcam, Cambridge, MA, USA),monoclonal mouse p47phox(1:500, Santa Cruz Biotechnology), monoclonal mouse GAPDH (1:5000, Abcam), monoclonal mouse COX-IV $(1 \mu \mathrm{g} / \mathrm{ml}$, Abcam), monoclonal rabbit $\mathrm{Na} / \mathrm{K}$ ATPase $(1: 100000$, Abcam) and monoclonal mouse $\beta$-actin $(1: 1000$, Santa Cruz Biotechnology). After the membranes were washed with TBST, incubated with a horseradish peroxidase-conjugated secondary antibody for $2 \mathrm{~h}$ at room temperature, the bands were exposed using an enhanced chemiluminescence (ECL) kit (Pierce Biotechnology, Rockford, IL, USA). Protein bands were visualized using ChemDocTM XRS with Quantity OneTM software (BioRad, Hercules, CA, USA). Blots were repeated at least three times for every condition. After development, the band intensities were quantified using Image-pro Plus 6.0 analysis software. The relative protein levels were calculated based on $\beta$-actin or GAPDH or $\mathrm{Na} / \mathrm{K}$ ATPase as the loading control.

\section{MDA level, glutathione peroxidase (GSH-PX) activity and ROS formation analysis}

The levels of MDA and activity of GSH-PX in the endothelial cells were measured using colorimetric kits (Nanjing Jiancheng Institute of Bio-engineering, Nanjing, China). Endothelial cells ROS formation was determined using dihydroethidium (DHE, Santa Cruz Biotechnology)-dependent fluorescence microtopography in aortic cryo-sections. Briefly, the sections were immersed in $10 \mu \mathrm{mol} / \mathrm{L}$ dihydroethidium (in PBS solution) in a humidified environment at room temperature for $30 \mathrm{~min}$. Dihydroethidium is oxidized by superoxide to form ethidium, which binds to DNA in the nucleus and emits red fluorescence. After washing with PBS three times, the sections were cover-slipped and then visualized under a fluorescence microscope (BX41, Olympus, Tokyo, Japan). Intensity of the DHE oxidation products' fluorescence was evaluated by densitometry.

\section{Real-time quantitative PCR analysis}

Total RNA was extracted from the endothelial cell homogenates with TRIzol Reagent (Takara, Shiga, Japan). The quantity and quality of the total RNA were determined by spectrophotometry. Then, $1 \mu \mathrm{g}$ of total RNA was reverse-transcribed to cDNA using the Reverse
Transcription System (Takara). Quantitative PCR analysis was carried out using an ABI Prism 7500 Sequence Detection System (Applied Biosystems, Foster City, CA, USA) with SYBR green PCR reagents (Takara). The primers for IL- 6 , TNF- $\alpha$, ICAM- 1 and $\beta$-actin were as follows: IL- 6 (sense 5'-TCGAGCCCACCGGGAACGAA-3'; antisense $5^{\prime}$-GCAACTGGACCGAAGGCGCT-3'); TNF- $\alpha$ (sense 5'-CGAGTCTGGGCAGGTCTACTTT-3'; antisense $5^{\prime}$-A GAGGTTGAGGGTGTCTGAAGG-3'); ICAM-1 (sense 5'-CCTTCCTCACCGTGTACTGG-3'; antisense 5'-AG CGTAGGGTAAGGTTCTTGC-3'); $\beta$-actin (sense $5^{\prime}$-GG AGATTACTGCCCTGGCTCCTA; antisense $5^{\prime}$-GACTC ATCGTACTCCTGCTTGCTG). Relative expression was normalized with $\beta$-actin.

\section{Statistical analysis}

Data are expressed as mean \pm standard deviation (SD). One-way analysis of variance (ANOVA) with a Tukey's post hoc test was performed to detect differences between the groups. Analyses of all data were performed using the SPSS software (version 13.0; SPSS, Chicago, IL, USA). $\mathrm{P}<0.05$ were considered statistically significant.

\section{Results}

An acute blood glucose fluctuation model was successfully established

In the AFG group, PG fluctuated between 5.5 and $20 \mathrm{mmol} / \mathrm{L}$. PG was maintained at $5.5 \mathrm{mmol} / \mathrm{L}$ for about $1 \mathrm{~h}$ and then at $20 \mathrm{mmol} / \mathrm{L}$ for another $1 \mathrm{~h}$ over a period of $48 \mathrm{~h}$ (Fig. 1).

\section{Insulin secretion and insulin resistance}

At the end of the $48 \mathrm{~h}$ infusion, insulin levels were significantly increased in the AFG and CHG groups in comparison with the SAL group $(\mathrm{P}<0.05$; Fig. 2a). The AFG group had higher insulin levels than the CHG group, but the difference was not statistically significant $(\mathrm{P}>0.05$; Fig. 2a). Insulin resistance, estimated as HOMA-IR, was higher in the AFG and CHG groups than that in the SAL group $(\mathrm{P}<0.05$; Fig. $2 \mathrm{~b})$. In contrast, $\beta$ cell function, estimated as HOMA- $\beta \%$ was lower in the AFG and CHG groups than that in the SAL group ( $\mathrm{P}<0.05$; Fig. $2 \mathrm{c})$. But neither the HOMA-IR nor HOMA- $\beta$ \% showed significant difference between the AFG and CHG group.

\section{Apoptosis of vascular endothelial cells}

The apoptosis of aorta vascular endothelial cells was detected using the TUNEL assay. In the AFG group, the apoptosis index was higher than the other two groups. But there is no differences between SAL and CHG group (Fig. 3). 

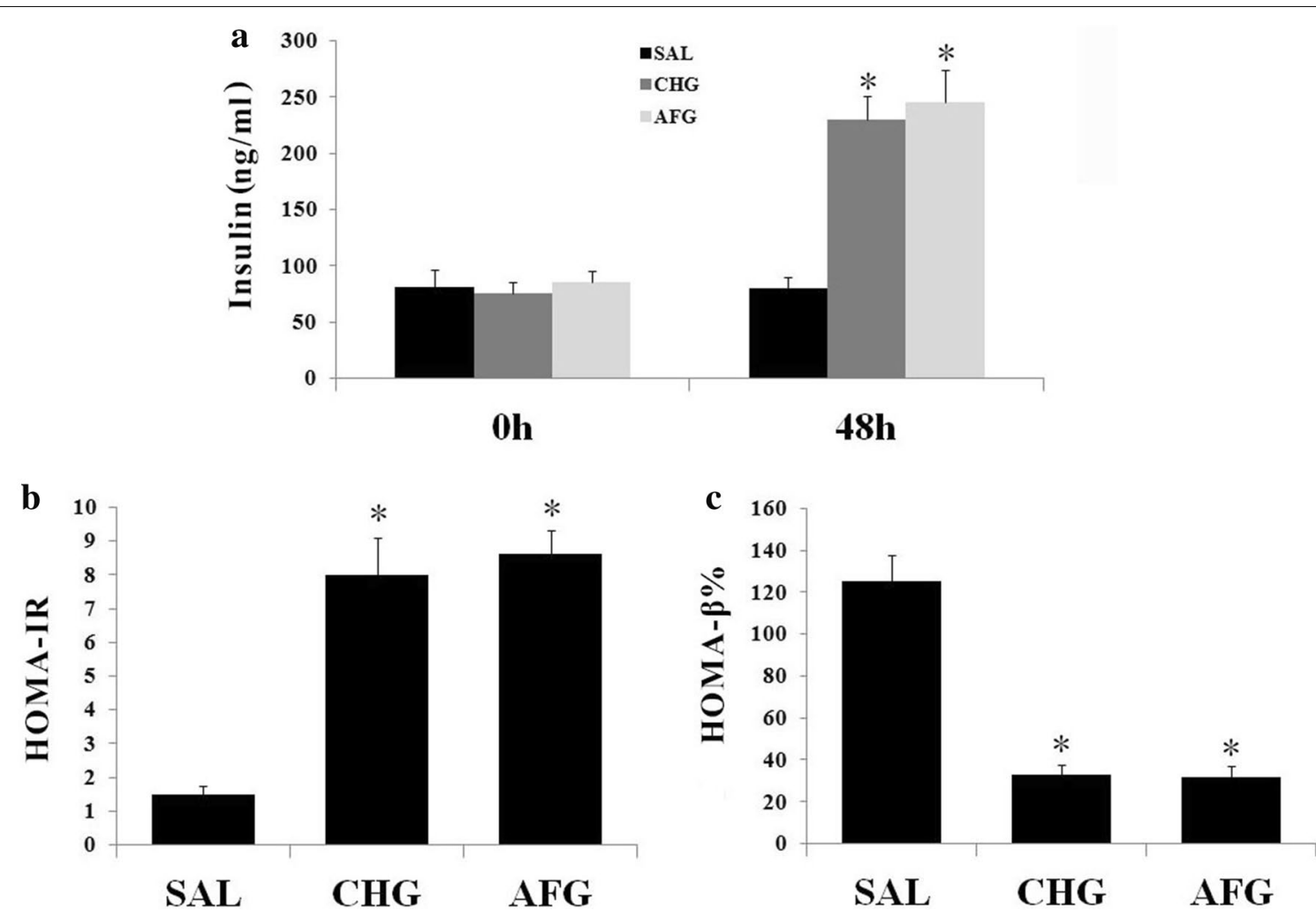

Fig. 2 Insulin secretion and insulin resistance. a Plasma insulin levels at the beginning and the end of the infusion. $\mathbf{b}$ Insulin resistance was estimated as HOMA-IR. c $\beta$ cell function was estimated as HOMA- $\beta \%$. SAL (SAL group rats underwent $48 \mathrm{~h}$ infusions with saline); $\mathrm{CHG}$ (CHG group rats underwent $48 \mathrm{~h}$ infusions with $50 \%$ glucose continually to keep the glucose concentration at $20 \pm 0.5 \mathrm{mmol} / \mathrm{l}$ ); AFG (AFG group rats underwent $48 \mathrm{~h}$ infusions with $50 \%$ glucose intermittently so that blood glucose alternated between $5.5 \pm 0.5$ and $20 \pm 0.5 \mathrm{mmol} / \mathrm{I})$. Data are mean \pm SD. $n=10$ /group. ${ }^{*} \mathrm{P}<0.05$ vs SAL

\section{Endothelial function}

As shown in Fig. 4, AFG caused endothelial dysfunction which resulted in a significant right-shift of the acetylcholine concentration-relaxation curve as observed by isometric tension studies $(\mathrm{P}<0.05)$. Vasodilator potency and efficacy were shown in Table 1 . Potency is $-\log$ EC50 and EC50 is the concentration that induces halfmaximal relaxation with respect to the maximal relaxation achieved with the highest concentration of the vasodilator used. Efficacy is defined as maximal relaxation obtained with the highest concentration of the vasodilator used. Endothelial function in the CHG group is worse than in the CHG group, but the difference was not statistically significant $(\mathrm{P}<0.05$; Fig. 4; Table 1$)$.

\section{Expression of $\mathrm{Bax}, \mathrm{Bcl}-2$, pro caspase- 3 and caspase-3 p17 proteins}

As shown in Fig. 5, total Bax, mitochondrial Bax and caspase-3 p17 protein levels in the CHG and AFG group were all significantly increased compared with the SAL group ( $\mathrm{P}<0.05$; Fig. 5a, b, d). Furthermore, the expression of total Bax, mitochondrial Bax and caspase-3 p17 in the AFG group was higher than that in the CHG group ( $\mathrm{P}<0.05$; Fig. 5a, b, d). In addition, both constant high glucose and acute blood glucose fluctuation decreased the levels of Bcl-2 and pro caspase- 3 protein when compared with the SAL group, and the AFG group had significantly reduced $\mathrm{Bcl}-2$ and pro caspase- 3 levels in comparison with the CHG group (both $\mathrm{P}<0.05$; Fig. 5 c, d respectively).

\section{Circulating 8-isoprostaglandin and MDA levels}

Circulating oxidative stress in this study was measured as the concentration of 8-isoprostaglandin and MDA. 8-isoprostaglandin is an in vivo oxidative stress marker, which is produced in a non-cyclooxygenase-dependent manner involving lipid peroxidation [23]. MDA, a marker of lipid peroxidation, was also measured. As shown in Fig. 6c and d, plasma 8-isoprostaglandin and MDA levels were significantly increased in the AFG and CHG groups in comparison with the SAL group $(\mathrm{P}<0.05)$. The levels of these two oxidative stress markers were also significantly higher in the AFG group than those in the CHG group $(\mathrm{P}<0.05$; Fig. 6c, d respectively). 


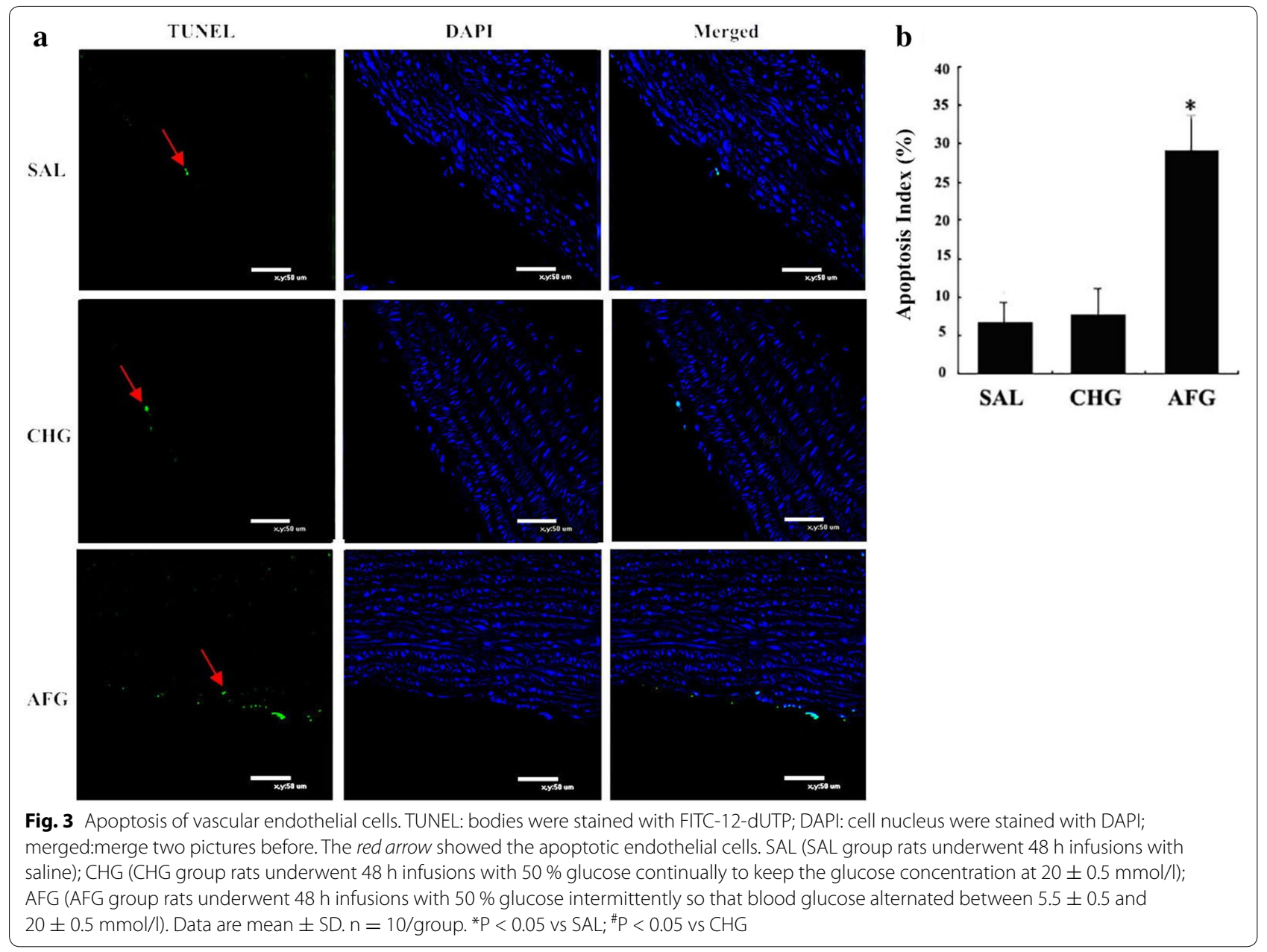

P47phox and 3-NT protein levels, MDA levels, GSH-PX activities, and ROS formation in vascular endothelial cells As shown in Fig. 6a, 3-NT protein levels in the CHG and AFG group were significantly increased compared with the SAL group, and the levels in the AFG group were higher than that in the CHG group $(\mathrm{P}<0.05$; Fig. 6a). Both the cytosolic and the membrane p47phox levels in the CHG and AFG group were significantly increased compared with the SAL group. Most importantly, the ratio of membrane-bound to cytosolic portion of p47phox was also increased in high glucose groups. In addition, the ratio was higher in the AFG group than that in the CHG group ( $\mathrm{P}<0.05$; Fig. $6 \mathrm{~b})$. As shown in Fig. 6e, the MDA levels in vascular endothelial cells were significantly increased in the AFG and CHG groups as compared with the SAL group $(\mathrm{P}<0.05)$. Moreover, the AFG group had higher MDA levels than the CHG group $(\mathrm{P}<0.05)$. On the contrary, the GSH-PX activities in vascular endothelial cells were decreased in the fluctuating condition compared with rats exposed to continually high glucose $(\mathrm{P}<0.05$, Fig. 6f). Furthermore, the GSH-PX activities in the CHG and AFG groups were lower than that of the SAL group $(P<0.05$, Fig. $6 f)$. Aortic ROS formation was detected in cryo-sections using DHE dependent fluorescent micro-topography (Fig. 6g), which was quantified by densitometry. Densitometric quantification of the DHE-derived ROS signal in the endothelium of vessels was shown in Fig. 4h. There was a significant increase in ROS formation in the endothelium of vessels from the CHG and AFG rats. And the levels of ROS formation were significantly higher in the AFG group than those in the $C H G$ group $(\mathrm{P}<0.05$; Fig. 6h).

\section{Plasma inflammatory cytokine concentrations}

The circulating levels of IL-6, TNF- $\alpha$, and ICAM- 1 increased significantly in the CHG and AFG groups compared with the SAL group $(\mathrm{P}<0.05$, Fig. 7$)$. In addition, the concentrations in the AFG group were higher than that of the $\mathrm{CHG}$ group $(\mathrm{P}<0.05$, Fig. 7$)$. 


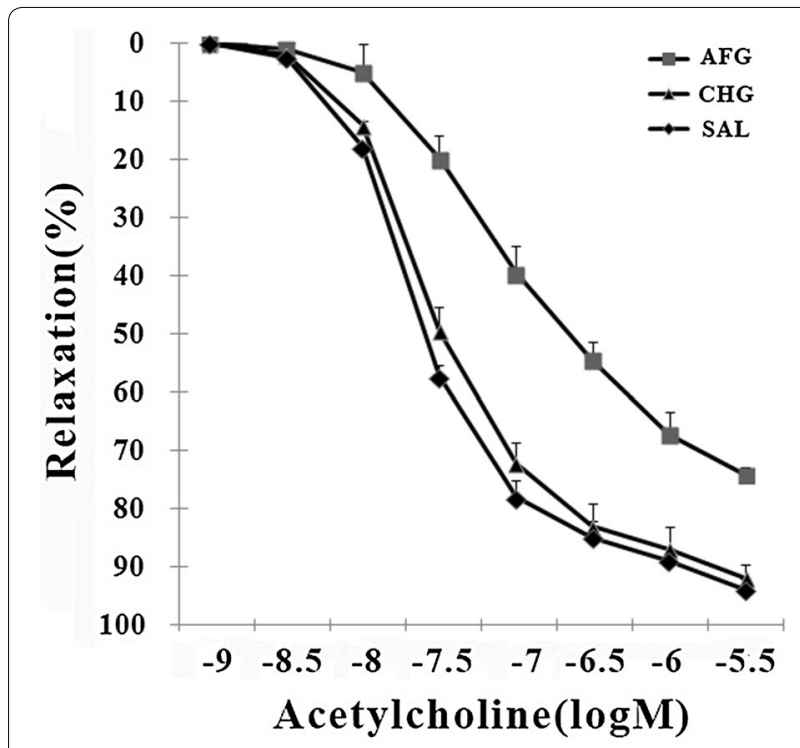

Fig. 4 Endothelium-dependent vascular relaxation by the vasodilators acetylcholine (ACh). SAL (SAL group rats underwent $48 \mathrm{~h}$ infusions with saline); $\mathrm{CHG}$ (CHG group rats underwent $48 \mathrm{~h}$ infusions with $50 \%$ glucose continually to keep the glucose concentration at $20 \pm 0.5 \mathrm{mmol} / \mathrm{l})$; AFG (AFG group rats underwent $48 \mathrm{~h}$ infusions with $50 \%$ glucose intermittently so that blood glucose alternated between $5.5 \pm 0.5$ and $20 \pm 0.5 \mathrm{mmol} / \mathrm{l})$. Data are mean $\pm \mathrm{SD}$. $n=10 /$ group

Table 1 Potencies and efficacies of the endotheliumdependent vasodilator acetylcholine (Ach) in rat aorta

\begin{tabular}{llll}
\hline Parameter & SAL & CHG & AFG \\
\hline Ach potency $\left(-\log \mathrm{EC}_{50}\right)$ & $7.9 \pm 0.05$ & $7.8 \pm 0.06$ & $7.2 \pm 0.08^{*}$ \\
Ach efficacy (max, relaxation, \%) & $98 \pm 1.2$ & $96 \pm 2.4$ & $75 \pm 1.8^{*}$ \\
\hline
\end{tabular}

SAL (SAL group rats underwent $48 \mathrm{~h}$ infusions with saline); $\mathrm{CHG}$ (CHG group rats underwent $48 \mathrm{~h}$ infusions with $50 \%$ glucose continually to keep the glucose concentration at $20 \pm 0.5 \mathrm{mmol} / \mathrm{l}$ ); AFG (AFG group rats underwent $48 \mathrm{~h}$ infusions with $50 \%$ glucose intermittently so that blood glucose alternated between $5.5 \pm 0.5$ and $20 \pm 0.5 \mathrm{mmol} / \mathrm{l}$ ). Data are mean $\pm S D . n=10 /$ group. * $\mathrm{P}<0.05$ vs SAL

\section{IL-6, TNF- $a$ and ICAM-1 mRNA expression in vascular endothelial cells}

In the CHG and AFG groups, IL-6, TNF- $\alpha$ and ICAM-1 mRNA expression was significantly higher than the SAL group $(\mathrm{P}<0.05$, Fig. 8$)$. The mRNA expression of all three cytokines was significantly higher in the AFG group compared to the CHG group $(\mathrm{P}<0.05$, Fig. 8$)$.

\section{Discussion}

The incidence of cardiovascular diseases in DM patients is significantly higher than in non-DM patients [24]. Vascular endothelial cell injury and dysfunction are important pathophysiological events in the occurrence and development of DM complications and cardiovascular events. Masaru Kuroda's study reported that compared with a marker of averaged blood glucose level such as HbA1c, mean amplitude of glycemic excursions (MAGE) was a more contributing factor of vascular injury [25]. Increasing evidence shows that fluctuant hyperglycemia is more harmful for the heart and vessels compared to persistent hyperglycemia $[3,26]$, but the specific mechanism remains poorly understood. Previous studies have focused on the influence of PG fluctuation on endothelial cells in vitro [13, 16, 18, 27, 28]; however, few in vivo studies have been conducted. In the present study, an in vivo model of acute fluctuant hyperglycemia was successfully established. In vivo and in vitro experiments have confirmed the effects of continual or intermittent high glucose on endothelial cells are unrelated to the hyperosmotic condition [13, 29]. In A. RISSO's study [13], Osmotic control was assured by incubating endothelial cells with $20 \mathrm{mmol} / \mathrm{l}$ mannitol, both continuously or in alternating fashion. Nonspecific effects due to osmolarity changes had be ruled out, because the cytotoxic effect was not detected in the cells cultured in the presence of $20 \mathrm{mmol} / \mathrm{l}$ mannitol, either continuously or in alternating fashion. It demonstrated that the effects of continual or intermittent high glucose are unrelated to the hyperosmotic condition. Our results showed that the $48 \mathrm{~h}$ persistent hyperglycemia did not cause apoptosis and dysfunction of vascular endothelial cells in vivo,while acute fluctuant hyperglycemia caused significantly apoptosis. But the Mechanism is not clear, the endothelial cell apoptosis and dysfunction are likely due to oxidative stress and inflammation effects,but may also be secondary to insulin resistance or $\beta$-cell dysfunction, and so on. In this study, both the AFG and CHG groups induced insulin resistance, and decreased the $\beta$-cell function. However, we observed that neither the HOMA-IR or HOMA- $\beta$ \% showed significant difference between the AFG and CHG group. Moreover, acute fluctuant hyperglycemia could significantly increase oxidative stress and inflammation of vascular endothelial cells in vivo compared to persistent hyperglycemia. So we speculated that, the endothelial cell apoptosis and injury are mainly associated with oxidative stress and inflammatory effects.

Although the impact of hyperglycemia on increasing the oxidative stress of endothelial cells has been confirmed [3, 30-32], few studies have compared the effects of intermittent and chronic hyperglycemia on vascular endothelial cell oxidative stress in vivo. Oxidative stress refers to the production of ROS, overwhelming their clearance and leading to their accumulation. A variety of pathological factors may cause excess production of ROS or reduced clearance of ROS, which disrupts the balance between oxidation and anti-oxidation, increases ROS in the blood and finally results in a oxidative status [33, 


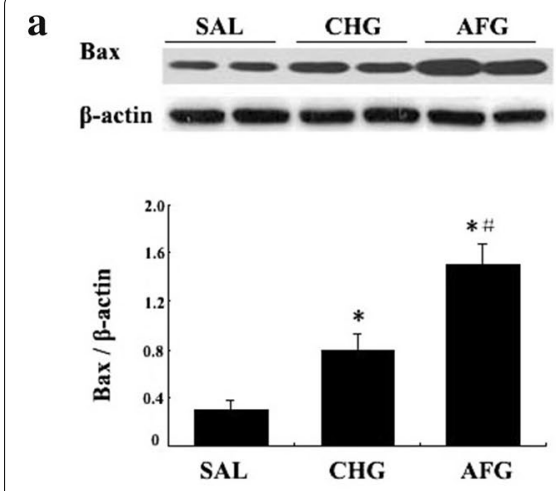

c
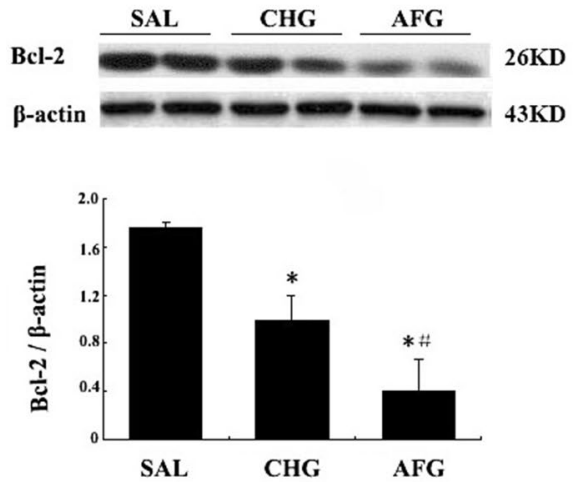

b
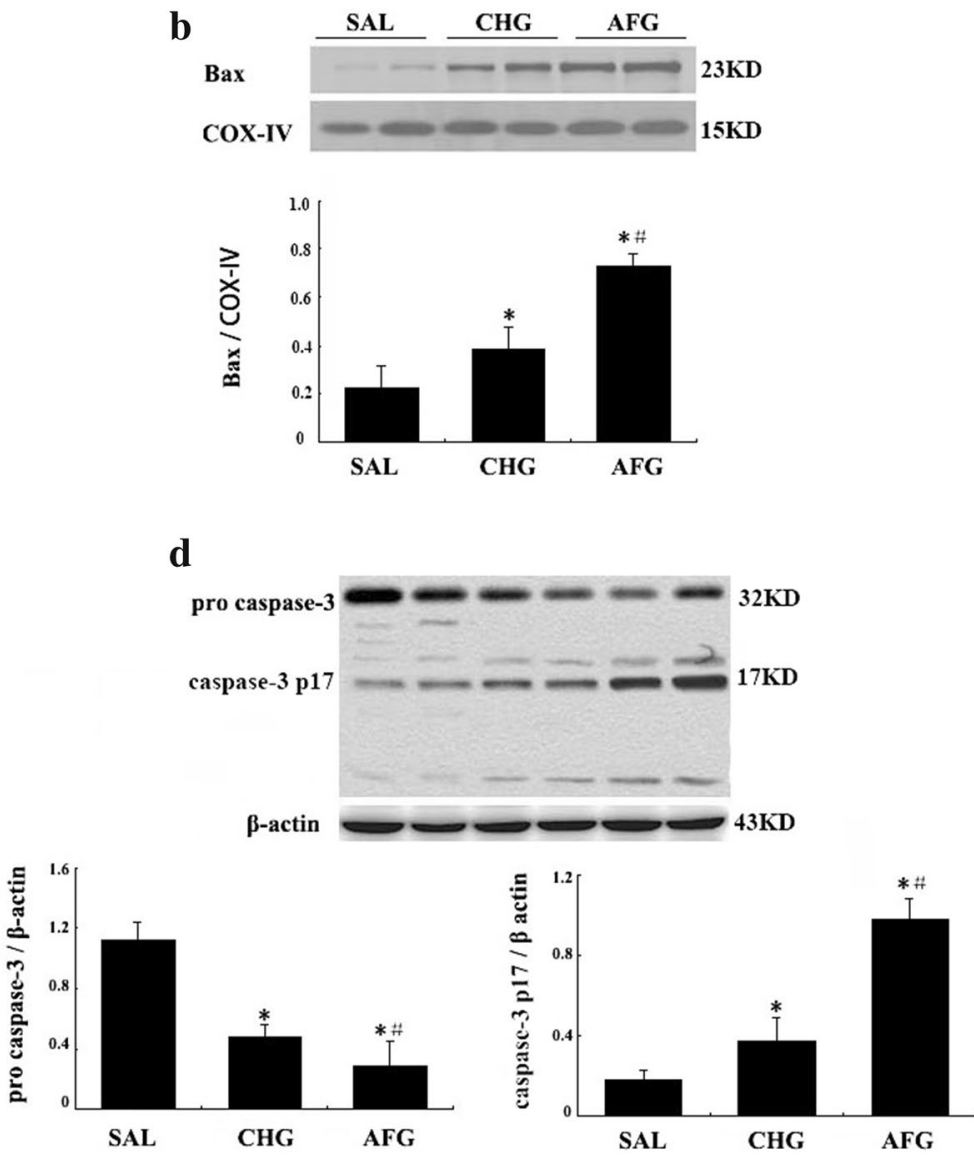

AFG

Fig. 5 Western blot analysis of Bax, Bcl-2, pro caspase-3 and caspase-3 p17 proteins in vascular endothelial cells. a Total bax protein expression in vascular endothelial cells. b Mitochondrial Bax protein expression in vascular endothelial cells. c Bcl-2 expression in vascular endothelial cells. d Pro caspase-3 and caspase-3 p17 expression in vascular endothelial cells. SAL (SAL group rats underwent 48 h infusions with saline); CHG (CHG group rats underwent $48 \mathrm{~h}$ infusions with $50 \%$ glucose continually to keep the glucose concentration at $20 \pm 0.5 \mathrm{mmol} / \mathrm{l})$; AFG (AFG group rats underwent $48 \mathrm{~h}$ infusions with $50 \%$ glucose intermittently so that blood glucose alternated between $5.5 \pm 0.5$ and $20 \pm 0.5 \mathrm{mmol} / \mathrm{l})$. $\beta$-Actin antibodies were used as loading controls. A representative western blot is shown. Data are mean \pm SD. $n=10$ /group. ${ }^{*} P<0.05$ vs SAL; ${ }^{P} P<0.05$ vs CHG

34]. Evidence indicates that oxidative stress is a major mechanism of vascular endothelial dysfunction, and ROS production increased significantly in persistent hyperglycemia, accompanied by reduced antioxidase activity, suggesting compromised anti-oxidative activity [3, 30-32]. In vitro studies show that fluctuant hyperglycemia may increase oxidative stress of human coronary endothelial cells [16]. Monnier et al. [3] found fluctuant hyperglycemia could also increase oxidative stress in the human body. P47phox is a cytosolic component of the NADPH oxidase, which could be activated or inactivated by the extra signal, thus to be the main enzyme responsible for ROS production. [22]. 3-NT is considered as a marker of peroxynitrite-mediated oxidative stress, which occurs during inflammation. MDA is a classic biomarker of oxidative stress and an aldehyde secondary to ROS-induced lipid peroxidation; its level may reflect the severity of oxidative stress and also may serve as an important pathological indicator [35]. GSH-PX is an important antioxidase, and the content and activity of GSH-PX may directly affect the concentration of ROS in cells [36]. Furthermore, plasma 8-isoprostaglandin represents a useful in vivo oxidative stress marker [23]. In the present study, acute fluctuant hyperglycemia dramatically increased the 3-NT expression,the MDA content,the ratio of membrane-bound to cytosolic portion of p47phox, and the ROS formation, while GSH-PX activity was reduced significantly, suggesting that oxidative stress is a major cause of endothelial injury. Furthermore, acute fluctuant hyperglycemia had a more potent capability to induce oxidative stress as compared to persistent hyperglycemia, which is consistent with previous findings [16].

Studies have shown that hyperglycemia may induce apoptosis of vascular endothelial cells in vitro $[13,16$, 


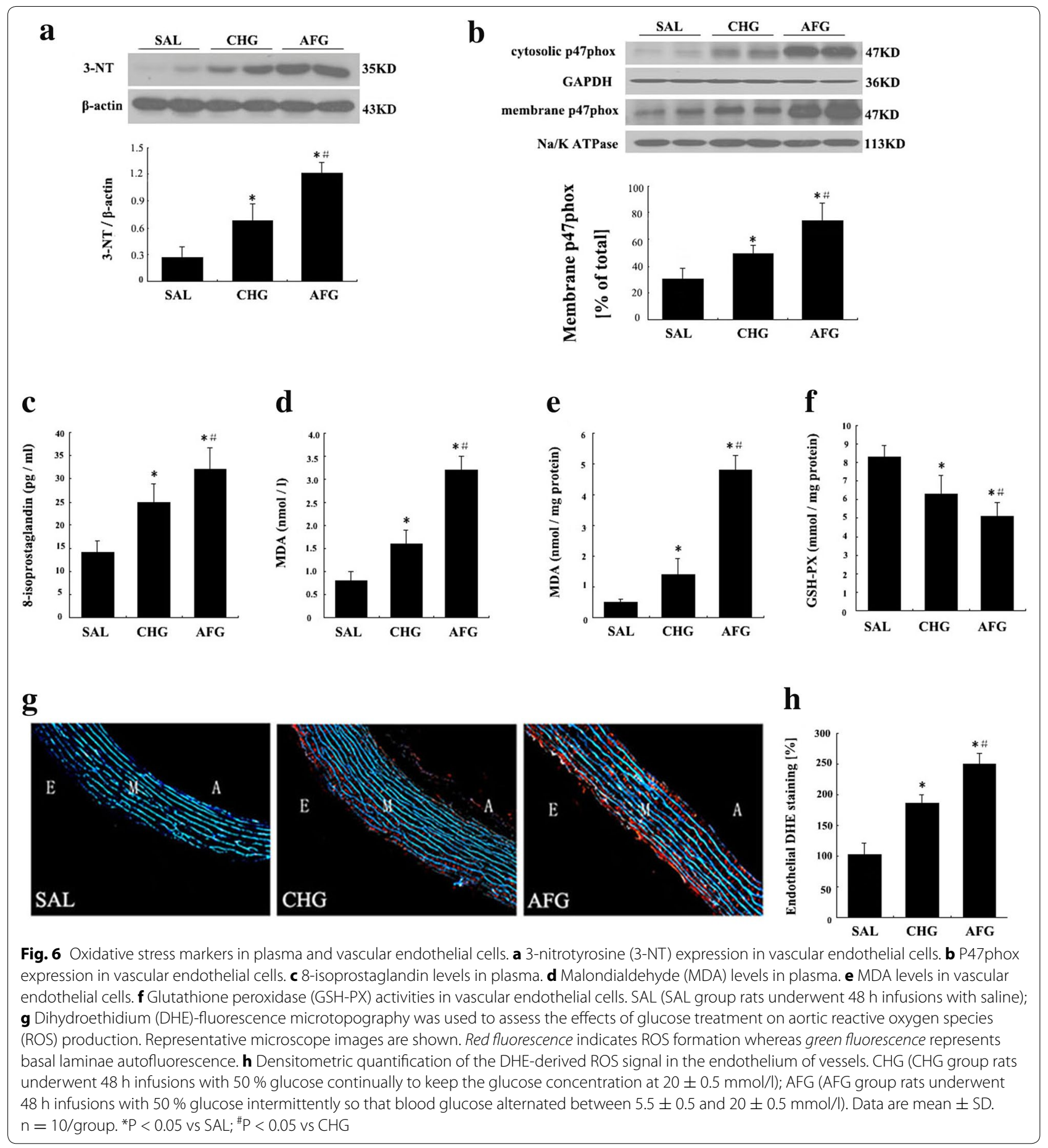

37-41]. In addition, transient fluctuant PG may also induce apoptosis of vascular endothelial cells, and more endothelial cells became apoptotic after fluctuant hyperglycemia than after persistent hyperglycemia $[13,14,16$, 39]. However, few studies have been conducted to investigate the influence of acute fluctuant hyperglycemia on apoptosis of endothelial cells in vivo. In the present study, acute fluctuant hyperglycemia significantly increased the number of apoptotic rat vascular endothelial cells and induced endothelial dysfunction; however, endothelial cell apoptosis and dysfunction was absent following persistent hyperglycemia. Furthermore, we detected the expression of the apoptosis-related proteins, $\mathrm{Bax}, \mathrm{Bcl}-2$, pro caspase-3 and caspase-3 p17, in endothelial cells. Bcl-2 and Bax are 

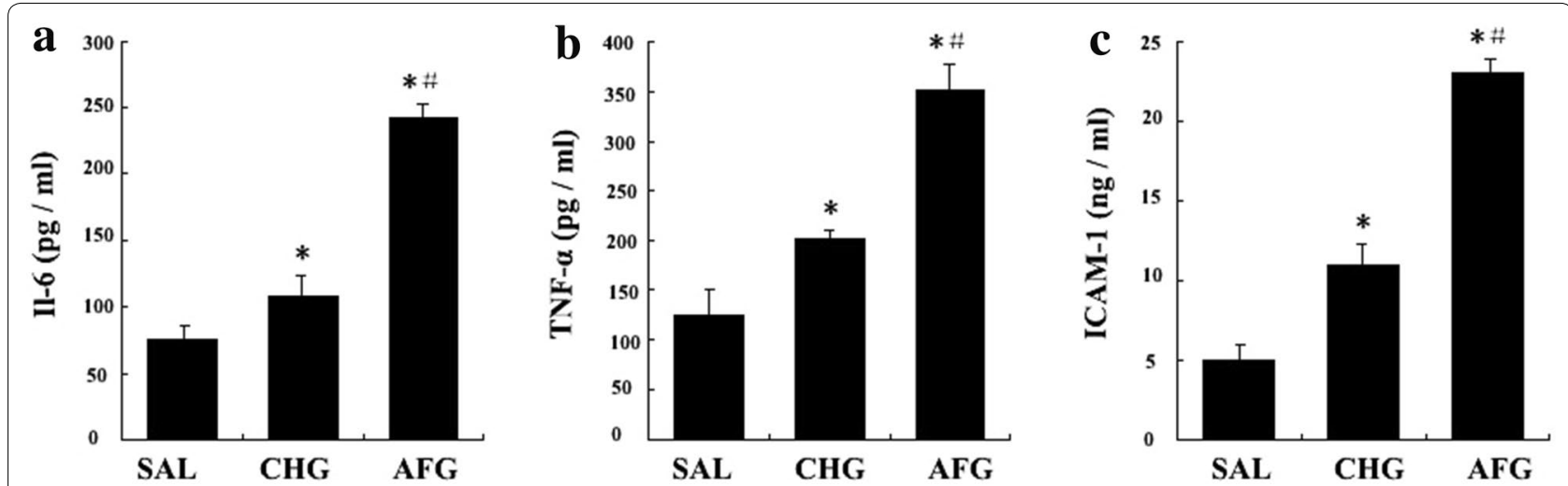

Fig. 7 ELISA analysis of IL-6, TNF-a and ICAM-1 in plasma. a The Circulating levels of Interleukin-6 (IL-6). b The Circulating levels of Tumor necrosis factor-a (TNF-a). c The Circulating levels of Intercellular adhesion molecule-1(ICAM-1). SAL (SAL group rats underwent $48 \mathrm{~h}$ infusions with saline); CHG (CHG group rats underwent $48 \mathrm{~h}$ infusions with $50 \%$ glucose continually to keep the glucose concentration at $20 \pm 0.5 \mathrm{mmol} / \mathrm{l})$; AFG (AFG group rats underwent $48 \mathrm{~h}$ infusions with $50 \%$ glucose intermittently so that blood glucose alternated between $5.5 \pm 0.5$ and $20 \pm 0.5 \mathrm{mmol} / \mathrm{l})$. Data are mean \pm SD. $n=10 /$ group. ${ }^{*} \mathrm{P}<0.05$ vs $S A L ; ~ \# P<0.05$ vs $C H G$
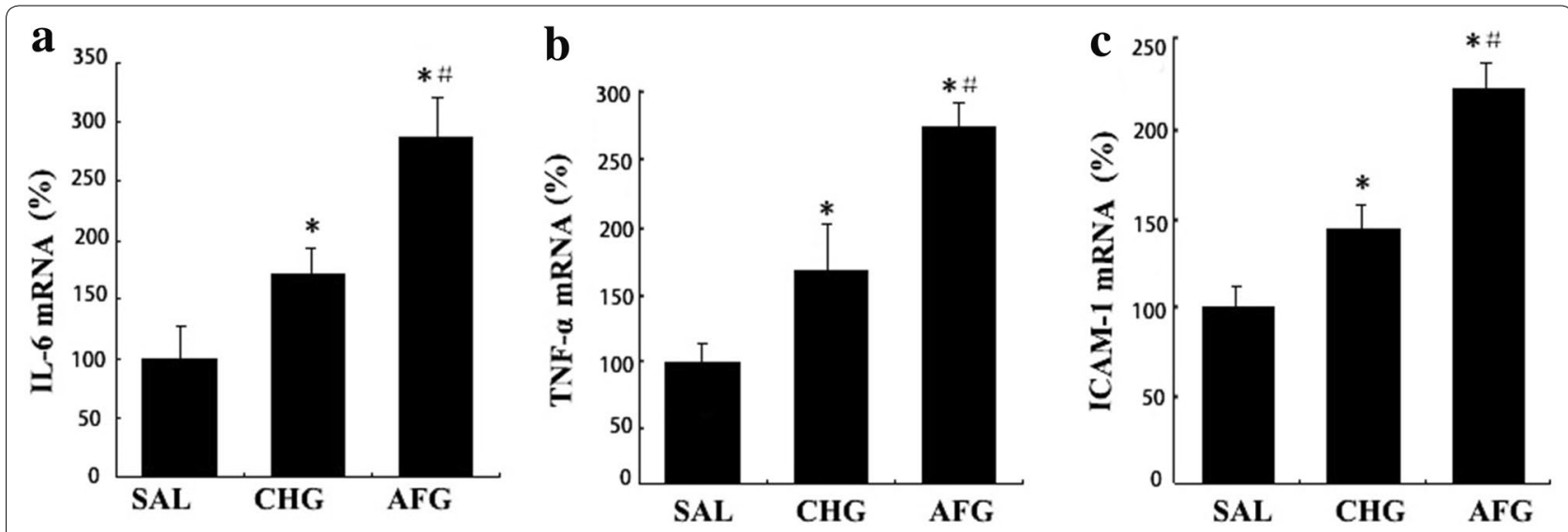

Fig. 8 Expression of IL-6, TNF-a and ICAM-1 mRNAs in vascular endothelial cells. a The mRNA expressions of Interleukin-6 (IL-6) in vascular endothelial cells. b The mRNA expressions of tumor necrosis factor-a (TNF-a) in vascular endothelial cells. $\mathbf{c}$ The mRNA expressions of intercellular adhesion molecule-1(ICAM-1) in vascular endothelial cells. CHG (CHG group rats underwent $48 \mathrm{~h}$ infusions with $50 \%$ glucose continually to keep the glucose concentration at $20 \pm 0.5 \mathrm{mmol} / \mathrm{l}$ ); AFG (AFG group rats underwent $48 \mathrm{~h}$ infusions with $50 \%$ glucose intermittently so that blood glucose alternated between $5.5 \pm 0.5$ and $20 \pm 0.5 \mathrm{mmol} / \mathrm{l})$. Data are mean $\pm \mathrm{SD} . \mathrm{n}=10$ /group. ${ }^{*} \mathrm{P}<0.05$ vs SAL; ${ }^{\#} \mathrm{P}<0.05$ vs CHG

the most important pair of proteins with opposite functions [42]. Mitochondrial translocation of Bax increases mitochondrial membrane permeability and consequently favors the release of apoptogenic factors, such as cytochrome $\mathrm{C}$, leading to the expression of caspase 3 [43]. Caspase- 3 is a crucial executive protease in the process of apoptosis [44]. Our results demonstrated that persistent hyperglycemia and fluctuant hyperglycemia significantly increased the expression of Bax protein and promoted its translocation to the outer mitochondrial membrane, and markedly reduced $\mathrm{Bcl}-2$ protein expression, which was accompanied by elevated expression of caspase- 3 p17. Of note, as compared to persistent hyperglycemia, fluctuant hyperglycemia increased Bax translocation to mitochondria and caspase-3 p17 expression and reduced Bcl-2 expression to greater levels. Taken together, both acute fluctuant hyperglycemia and persistent hyperglycemia may initiate the apoptosis and dysfunction of endothelial cells, but persistent hyperglycemia failed to significantly induce endothelial apoptosis and dysfunction, which might be ascribed to the short-term exposure to hyperglycemia used in this study. Thus, we speculate that acute fluctuant hyperglycemia is more harmful to endothelial cells than persistent hyperglycemia.

There is a growing body of evidence for the complex involvement of inflammation in DM and its resultant 
cardiovascular complications [18]. Prabhakaran Kumar et al. [45] demonstrated that high glucose could regulate the expression of IL- 6 and IL-17 family cytokines transcriptionally through oxidative stress and NF- $\mathrm{kB}$ activation via PKC and p38 MAPK signaling pathways. Finally, high glucose also increases the adhesion of lymphocytes to endothelial surfaces and thereby promoting the pathogenesis of atherosclerosis [45]. Pro-inflammatory cytokines, such as IL- 6 and TNF- $\alpha$, play important roles in the occurrence and development of vascular atherosclerosis [46-48]. It has also been widely accepted that the adhesion of monocytes and macrophages to endothelial cells is crucial for the pathogenesis of atherosclerosis [49]. ICAM-1 is an important adhesion molecule, mediating intercellular adhesion. In vascular endothelial cells, basal ICAM-1 expression is at a low level. ICAM-1 may bind to the specific receptor on vascular endothelial cells to exert its biological effects. In studies using umbilical vein endothelial cells, fluctuant hyperglycemia could significantly increase the content of IL-6, TNF- $\alpha$ and ICAM-1 in vitro $[15,17,18,50]$. Esposito et al. [51] also found that fluctuant hyperglycemia could induce TNF- $\alpha$ production in the blood of human in vivo. Previous study have shown that high glucose altered the expression profile of cytokines/chemokines via specific signaling pathways and can increase monocyte-endothelial adhesion in monocytes [52]. In our study, an acute increase in PG could increase the plasma levels of IL- 6 , TNF- $\alpha$ and ICAM- 1 and their expression by vascular endothelial cells, and greater inductions were observed following exposure to fluctuant hyperglycemia. Thus, for the first time, our study indicates that acute fluctuant hyperglycemia has a more potent ability to increase pro-inflammatory cytokines production in vivo as compared to persistent hyperglycemia, which is consistent with previous studies in vitro [15, $17,18,50]$. In summary, our results indicate that acute fluctuant hyperglycemia is likely to induce more severe inflammation and may be more harmful to the cardiovascular system as compared to persistent hyperglycemia.

\section{Conclusion}

Taken together, our results confirm that fluctuant hyperglycemia may significantly increase oxidative stress and inflammation in endothelial cells, elevate the adhesion of monocytes to endothelial cells, increase endothelial cell apoptosis and dysfunction, and cause more severe cardiovascular injury in vivo. It suggests that glucose fluctuation could have a more ominous impact on the function of endothelial cells to promote atherosclerosis. Therefore, not only lowering blood glucose, but also reducing glucose fluctuation is very important in clinic. Based on the control of blood glucose fluctuation, anti-oxidative and anti-inflammatory therapies may provide an alternative for the treatment of fluctuant hyperglycemia-induced cardiovascular diseases.

\section{Abbreviations \\ DM: diabetes mellitus; PG: plasma glucose; HCAECs: human coronary artery endothelial cells; SAL: saline; CHG: constant high glucose; AFG: acute blood glucose fluctuation; RIAs: radioimmunoassays; HOMA-IR: homeostasis model of assessment for insulin resistence index; ELISA: enzyme-linked immunosorb- ent assay; MDA: malondialdehyde; IL-6: interleukin-6; TNF-a: tumor necrosis factor-a; ICAM-1: intercellular adhesion molecule-1; ROS: reactive oxygen species; TUNEL: terminal deoxynucleotidyl transferase dUTP nick end labeling; Ach: acetylcholine; Bcl-2: B-cell lymphoma-2; Bax: B-cell lymphoma-2 associ- ated X protein; 3-NT: 3-nitrotyrosine; GSH-PX: glutathione peroxidase.}

\section{Authors' contributions}

NW was responsible for the design conception of the experiments, collection, analysis and interpretation of the data, and drafting of the manuscript. HS was responsible for the interpretation of the data and drafting of the manu-

script. HL, YW and YB contributed to perform experiments. PH was principal investigator of the study, contributed to the analysis and interpretation of the results, and produced the final version of the manuscript. All authors read and approved the final manuscript.

\section{Author details}

${ }^{1}$ Department of Endocrinology, Shengjing Hospital of China Medical University, Shenyang 110004, China. ${ }^{2}$ Department of Emergency, Shengjing Hospital of China Medical University, Shenyang 110004, China. ${ }^{3}$ Department of Ophthalmology, Shengjing Hospital of China Medical University, Shenyang 110004, China.

\section{Acknowledgements}

We gratefully acknowledge Xiaowei Wei for technical support.

\section{Competing interests}

The authors declare that they have no competing interests.

\section{Availability of data and materials}

The datasets supporting the conclusions of this article are included within the article.

\section{Ethics approval and consent to participate}

All animal experiments were performed with approval from the animal ethics committee of Shengjing Hospital of China Medical University (2016PS026 K).

\section{Funding}

The design of the study and collection, analysis, and interpretation of data and writing of this manuscript was supported by a Research Fund for Project of Liaoning Provincial Educational Bureau (Grant no. 20160630).

Received: 14 March 2016 Accepted: 22 July 2016

Published online: 05 August 2016

\section{References}

1. Hirsch IB. Glycemic variability: it's not just about A1C anymore! Diabetes Technol Ther. 2005;7:780-3.

2. Matthews DR, Stratton IM, Aldington SJ, Holman RR, Kohner EM, UK Prospective Diabetes Study Group. Risks of progression of retinopathy and vision loss related to tight blood pressure control in type 2 diabetes mellitus: UKPDS 69. Arch Ophthalmol. 2004;122:1631-40.

3. Monnier L, Mas E, Ginet C, Michel F, Villon L, Cristol JP, et al. Activation of oxidative stress by acute glucose fluctuations compared with sustained chronichyperglycemia in patients with type 2 diabetes. JAMA. 2006;295:1681-7.

4. Group TDs. Glucose tolerance and mortality: comparison of WHO and American Diabetic Association diagnostic criteria. The Lancet. 1999;354(9179):617-21. 
5. Zhang W, Zhao S, Li Y, Peng G, Han P. Acute blood glucose fluctuation induces myocardial apoptosis through oxidative stress and nuclear factor-KB activation. Cardiology. 2013;124:11-7.

6. Zhao $S$, Zhang W, LiY, He B, Han P. Effect of blood glucose fluctuation on apoptosis of rat hepatocytes in vivo. General Endocrinologica. 2011;7:325-36.

7. Oelze M, Daiber A, Brandes RP, Hortmann M, Wenzel P, Hink U, et al. Nebivolol inhibits superoxide formation by NADPH oxidase and endothelial dysfunction in angiotensin II-treated rats. Hypertension. 2006:48:677-84.

8. Lorenzi M, Cagliero E. Pathobiology of endothelial and other vascular cells in diabetes mellitus. Diabetes. 1991:40:653-9.

9. Cohen RA. Dysfunction of vascular endothelium in diabetes mellitus. Circulation. 1993;87(Suppl V):V67-76.

10. Oelze M, Mollnau H, Hoffmann N, Warnholtz A, Bodenschatz M, Smolenski A, et al. Vasodilator-stimulated phosphoprotein serine 239 phosphorylation as a sensitive monitor of defective nitric oxide/cGMP signaling and endothelial dysfunction. Circ Res. 2000;87:999-1005.

11. Oelze M, Kröller-Schön S, Welsch of P, Jansen T, Hausding M, Mikhed $Y$, et al. The sodium-glucose co-transporter 2 inhibitor empagliflozin improves diabetes-induced vascular dysfunction in the streptozotocin diabetes rat model by interfering with oxidative stress and glucotoxicity PLOS ONE. 2014:9:e112394.

12. Jay D, Hitomi H, Griendling KK, Jay D, Hitomi H. D, H, KK. Oxidative stress and diabetic cardiovascular complications. Free Radic Biol Med. 2006:40:183-92

13. Risso A, Mercuri F, Quagliaro L, Damante G, Ceriello A. Intermittent high glucose enhances apoptosis in human umbilical vein endothelial cells in culture. Am J Physiol Endocrinol Metab. 2001;281:E924-30.

14. Schisano B, Tripathi G, McGee K, McTernan PG, Ceriello A. Glucose oscillations, more than constant high glucose, induce p53 activation and a metabolic memory in humanendothelial cells. Diabetologia. 2011;54:1219-26.

15. Piconi L, Quagliaro L, Da Ros R, Assaloni R, Giugliano D, Esposito K, et al. Intermittent high glucose enhances ICAM-1, VCAM-1, E-selectin and interleukin-6 expression in human umbilical endothelial cells in culture: the role of poly(ADP-ribose) polymerase. J Thromb Haemost. 2004;2:1453-9.

16. Liu TS, Pei YH, Peng YP, Chen J, Jiang SS, Gong JB. Oscillating high glucose enhances oxidative stress and apoptosis in human coronary arteryendothelial cells. J Endocrinol Invest. 2014;37:645-51.

17. Quagliaro L, Piconi L, Assaloni R, Da Ros R, Maier A, Zuodar G, et al. Intermittent high glucose enhances ICAM-1, VCAM-1 and E selectin expression in human umbilical veinendothelial cells in culture:the distinct role of protein kinase $\mathrm{C}$ and mitochondrial superoxide production. Atherosclerosis. 2005;183:259-67.

18. Liu T, Gong J, Chen Y, Jiang S. Periodic vs constant high glucose in inducing pro-inflammatory cytokine expression in humancoronary artery endothelial cells. Inflamm Res. 2013;62:697-701.

19. Mita T, Otsuka AK, Uchida T, Ogihara T, Fujitani Y, Hirose T, et al. Swings in blood glucose levels accelerate atherogenesis in apolipoprotein E-deficient mice. Biochem Biophys Res Commun. 2007;358:679-85

20. Han P, Zhang YY, Lu Y, He B, Zhang W, Xia F. Effects of different free fatty acids on insulin resistance in rats. Hepatobiliary Pancreat Dis Int. 2008;7:91-6.

21. Li H, Li H, Bao Y, Zhang X, Yu Y. Free fatty acids induce endothelial dysfunction and activate protein kinase $\mathrm{C}$ and nuclear factor-kB pathway in rat aorta. Int J Cardiol. 2011;152:218-24.

22. Wenzel P, Schulz EM, Muller J, Schuhmacher S, Alhamdani M, Debrezion J, et al. AT1-receptor blockade by telmisartan upregulates GTP-cyclohydrolase I and protects eNOS in diabetic rats. Free Radic Biol Med. 2008:45:619-26.

23. Morrow JD. Quantification of isoprostanes as indices of oxidant stress and the risk of atherosclerosis in humans. Arterioscler Thromb Vasc Biol. 2005;25:279-86.

24. Jax TW, Peters AJ, Plehn G, Schoebel FC. Relevance of hemostatic risk factors on coronary morphology in patients with diabetes mellitus type 2. Cardiovasc Diabelol. 2009;8:24.

25. Kuroda M, Shinke T, Sakaguchi K, Otake H, Takaya T, Hirota Y, et al. Association between daily glucose fluctuation and coronary plaque properties in patients receiving adequatelipidlowering therapy assessed by continuous glucose monitoring and optical coherence tomography. Cardiovasc Diabetol. 2015;11(14):78.
26. Azuma K, Kawamori R, Toyofuku Y, Kitahara Y, Sato F, Shimizu T, et al. Repetitive fluctuations in blood glucose enhance monocyte adhesion to the endothelium of ratthoracic aorta. Arterioscler Thromb Vasc Biol. 2006;26:2275-80

27. Piconi L, Quagliaro L, Assaloni R, Da Ros R, Maier A, Zuodar G, et al. Constant and intermittent high glucose enhances endothelial cell apoptosis through mitochondrial superoxide overproduction. Diabetes Metab Res Rev. 2006;22:198-203.

28. Quagliaro L, Piconi L, Assaloni R, Martinelli L, Motz E, Ceriello A. Intermittent high glucose enhances apoptosis related to oxidative stress in human umbilical vein endothelial cells: the role of protein kinase $C$ and NAD(P)H-oxidase activation. Diabetes. 2003;52:2795-804.

29. Tang C, Han P, Oprescu Al, Lee SC, Gyulkhandanyan AV, Chan GN, et al. Evidence for a role of superoxide generation in glucose-induced beta-cell dysfunction in vivo. Diabetes. 2007;56:2722-31.

30. Suh SW, Gum ET, Hamby AM, Chan PH, Swanson RA. Hypoglycemic neuronal death is triggered by glucose reperfusion and activation of neuronal NADPH oxidase. J Clin Invest. 2007:117:910-8.

31. Ulker S, McMaster D, McKeown PP, Bayraktutan U. Antioxidant vitamins C and $\mathrm{E}$ ameliorate hyperglycaemia-induced oxidative stress in coronaryendothelial cells. Diabetes Obes Metab. 2004;6:442-51.

32. Weidig P, McMaster D, Bayraktutan U. High glucose mediates pro-oxidant and antioxidant enzyme activities in coronary endothelial cells. Diabetes Obes Metab. 2004;6:432-41.

33. Apel K, Hirt H. Reactive oxygen species: metabolism, oxidative stress, and signal transduction. Annu Rev Plant Biol. 2004;55:373-99.

34. Finkel T, Holbrook NJ. Oxidants, oxidative stress and the biology of ageing. Nature. 2000;408:239-47.

35. Draper $\mathrm{HH}$, Hadley M. Malondialdehyde determination as index of lipid peroxidation. Methods Enzymol. 1990;186:421-31.

36. Dursun E, Dursun B, Suleymanlar G, Ozben T. Effect of haemodialysis on the oxidative stress and antioxidants in diabetes mellitus. Acta Diabetol. 2005:42:123-8.

37. Baumgartner-Parzer SM, Wagner L, Pettermann M, Grillari J, Gessl A, WaldhäusI W. High-glucose-triggered apoptosis in cultured endothelial cells. Diabetes. 1995;44:1323-7.

38. Du XL, Sui GZ, Stockklauser-Färber K, Weiss J, Zink S, Schwippert B, et al. Introduction of apoptosis by high proinsulin and glucose in cultured human umbilical vein endothelial cells ismediated by reactive oxygen species. Diabetologia. 1998;41:249-56.

39. Xiao X, Dong Y, Zhong J, Cao R, Zhao X, Wen G, Liu J. Adiponectin protects endothelial cells from the damages induced by the intermittent high level of glucose. Endocrine. 2011;40:386-93.

40. Wang W, Wang Y, Long J, Wang J, Haudek SB, Overbeek P, et al. Mitochondrial fission triggered by hyperglycemia is mediated by ROCK1 activation in podocytesand endothelial cells. Cell Metab. 2012;15:186-200.

41. Ungvari Z, Bailey-Downs L, Gautam T, Jimenez R, Losonczy G, Zhang C, Ballabh P, et al. Adaptive induction of NF-E2-related factor-2-driven antioxidant genes in endothelial cells inresponse to hyperglycemia. Am J Physiol Heart Circ Physiol. 2011;300:H1 133-40.

42. Yang E, Zha J, Jockel J, Boise LH, Thompson CB, Korsmeyer SJ. Bad, a heterodimeric partner for $\mathrm{BCl}-\mathrm{XL}$ and $\mathrm{BCl}-2$, displaces Bax andpromotes cell death. Cell. 1995;80:285-91.

43. Luo T, Chen B, Zhao Z, He N, Zeng Z, Wu B. Histamine H2 receptor activation exacerbates myocardial ischemia/reperfusion injury by disturbing mitochondrial and endothelial function. Archiv Für Kreislaufforschung. 2013;108:342-56.

44. Cheng EH, Wei MC, Weiler S, Flavell RA, MakTW, Lindsten T, et al. BCL-2, $B C L-X(L)$ sequester $B H 3$ domain-only molecules preventing $B A X$ - and BAK-mediated mitochondrialapoptosis. Mol Cell. 2001;8:705-11.

45. Kumar P, Natarajan K, Shanmugam N. High glucose driven expression of pro-inflammatory cytokine and chemokine genes in lymphocytes: molecular mechanisms of IL-17 family gene expression. Cell Signal. 2013;26:528-39.

46. Hou T, Tieu BC, Ray S, Recinos lii A, Cui R, Tilton RG, et al. Roles of IL-6-gp130 signaling in vascular inflammation. Curr Cardiol Rev. 2008:4:179-92.

47. Schuett H, Luchtefeld M, Grothusen C, Grote K, Schieffer B. How much is too much? Interleukin- 6 and its signalling in atherosclerosis. Thromb Haemost. 2009;102:215-22. 
48. Bruunsgaard H, Skinhoj P, Pedersen AN, Schroll M, Pedersen BK. Ageing, tumour necrosis factor-alpha (TNF-alpha) and atherosclerosis. Clin Exp Immunol. 2000;121:255-60.

49. Jiang $Y$, Jiang $L L$, Maimaitirexiati $X M$, Zhang $Y$, Wu L. Irbesartan attenuates TNF-a-induced ICAM-1, VCAM-1, and E-selectin expression through suppression of NF-KB pathway in HUVECs. Eur Rev Med Pharm acol Sci. 2015;19:3295-302.

50. Omi H, Okayama N, Shimizu M, Okouchi M, Ito S, Fukutomi T, et al. Participation of high glucose concentrations in neutrophil adhesion and surface expression of adhesion molecules on cultured human endothelial cells: effect of antidiabetic medicines. J Diabetes Complic. 2002;16:201-8

51. Esposito K, Nappo F, Marfella R, Giugliano G, Giugliano F, Ciotola M, et al. Inflammatory cytokine concentrations are acutely increased by hyperglycemia in humans: role of oxidative stress. Circulation. 2002;106:2067-72.

52. Shanmugam N, Reddy MA, Guha M. R Natarajan. High Glucose-Induced Expression of Proinflammatory Cytokine and Chemokine Genes in Monocytic Cells. Diabetes. 2003;52:248-9.

\section{Submit your next manuscript to BioMed Central and we will help you at every step:}

- We accept pre-submission inquiries

- Our selector tool helps you to find the most relevant journal

- We provide round the clock customer support

- Convenient online submission

- Thorough peer review

- Inclusion in PubMed and all major indexing services

- Maximum visibility for your research

Submit your manuscript at www.biomedcentral com/submit 